Copyright by the American Society of Agricultural and Biological Engineers. Harpold, A. A.; Mostaghimi, S.; Vlachos, P. P.; Brannan, K.; Dillaha, T., "Stream discharge measurement using a large-scale particle image velocimetry (LSPIV) prototype," Transactions of the ASABE. 49(6): 1791-1805. (doi: 10.13031/2013.22300) @2006

\title{
Stream Discharge Measurement Using a Large-Scale Particle Image Velocimetry (LSPIV) Prototype
}

\author{
A. A. Harpold, S. Mostaghimi, P. P. Vlachos, K. Brannan, T. Dillaha
}

\begin{abstract}
New technologies have been developed for open-channel discharge measurement due to concerns about costs, accuracy, and safety of traditional methods. One emerging technology is large-scale particle image velocimetry (LSPIV). LSPIV is capable of measuring surface velocity by analyzing recorded images of particles added to the stream surface. LSPIV has several advantages over conventional measurement techniques: LSPIV is safer, potentially automated, and produces real-time measurements. Therefore, the goal of this study was to evaluate the accuracy and feasibility of using LSPIV to measure instantaneous discharge in low-order streams. The specific objectives were: (1) to determine optimum operating parameters for applying LSPIV under various conditions, (2) to design, develop, and test a prototype under controlled laboratory conditions, and (3) to develop and test the field equipment for a variety of stream flow conditions. The laboratory experiment results indicated that LSPIV accuracy was influenced by camera angle, surface disturbances (Froude number), and flow tracer concentration. Under field conditions, the prototype acquired consistent images and performed image processing using accepted input parameters. The accuracy of LSPIV for use in field applications was evaluated using a permanent weir. Overall, 18 discharge measurements were taken with each measuring device. The LSPIV prototype was accurate, with a mean error of $-1.7 \%$, compared to the weir measurements. The root mean square error (RMSE) was similar for LSPIV and current meter discharge measurements with the area-velocity method when compared to the weir. Finally, the LSPIV discharge measurements had an uncertainty of approximately $\pm 14 \%$ (at a 95\% confidence level). Therefore, LSPIV showed the potential to become competitive with conventional discharge measurement techniques.
\end{abstract}

Keywords. Discharge, LSPIV, Monitoring, Stream.

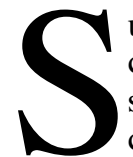
urface runoff, specifically open-channel flow, is a component of the hydrologic cycle that can be measured for large geographic areas with reasonable accuracy (Herschy, 2002). Flow information is necessary for water management in many diverse applications, including water supply management, pollution control, irrigation, flood control, energy generation, and industrial use (Herschy, 2002). Field measurement of flow, however, can be quite challenging, based on site and flow conditions.

Stream gauging stations have been used as the standard method of measuring open-channel flow for over 100 years (Costa et al., 2002). At gauging stations, typically the depth of flow above an arbitrary point in the channel (stage) is measured, and flow rate is estimated using a stage-discharge relationship. If a calibrated control structure is not installed in the stream, then the channel dimensions are surveyed and discharge is usually measured using current meters or acoustic Doppler velocimetry (ADV) (Yorke and Oberg,

Submitted for review in March 2006 as manuscript number SW 6409; approved for publication by the Soil \& Water Division of ASABE in August 2006.

The authors are Adrian A. Harpold, Graduate Student, Saied Mostaghimi, ASABE Member Engineer, Professor and Department Head, Kevin Brannan, ASABE Member Engineer, Research Scientist, and Theo Dillaha, ASABE Member Engineer, Professor, Department of Biological Systems Engineering, Virginia Tech, Blacksburg, Virginia; and Pavlos Vlachos, Assistant Professor, Department of Mechanical Engineering, Virginia Tech, Blacksburg, Virginia. Corresponding author: Adrian Harpold, 30 Riley-Robb Hall, Cornell University, Ithaca, NY 14853; phone: 607-342-3353; e-mail: aah38@cornell.edu.
2002). Flow measurements, across the range of flow conditions, are used to develop a site-specific stage-discharge relationship. Continuous flow monitoring is generally a labor-intensive and costly endeavor (Grant, 1997). Consequently, funding constraints often limit the capacity to expand the number of gauging stations.

New technologies have been developed for the establishment of stage-discharge relationships due to concerns about the costs, accuracy, and safety of traditional discharge estimation methods (Grant, 1997). The U.S. Geological Survey (USGS) is investigating technologies for direct, continuous, non-contact measurement of open-channel discharge (Melcher et al., 2002). Research by Costa et al. (2002) showed that it is possible to measure discharge with non-contact methods that maintain accuracy levels equivalent to those of conventional methods. The USGS and other researchers have suggested that large-scale particle image velocimetry (LSPIV) is a promising technology for non-contact remote instantaneous flow measurement (Bradley et al., 2002; Melcher et al., 2002; Cruetin et al., 2003).

Large-scale particle image velocimetry is capable of measuring surface velocity by collecting and analyzing recorded images of the flow field (the stream surface). The LSPIV system tracks the movement of tracers on the water surface through successive images using statistical correspondence. Cross-correlation algorithms divide the image into small interrogation areas, each producing one displacement vector. The velocity is the ratio of the particle displacement divided by the elapsed time between images. A representative stream velocity is then estimated using a correction factor to account for channel roughness. Finally, 
stream discharge is estimated using an area-velocity method. LSPIV is an offshoot of conventional PIV, classical flow visualization, and laser speckle velocimetry (Adrian, 1991).

Significant work has been done to refine methodologies and techniques involved in particle image velocimetry (PIV), but its large-scale application to open-channel flow measurement (LSPIV) is more recent. Therefore, only limited amounts of field data are available to verify the accuracy of LSPIV velocity measurements. Research conducted by Bradley et al. (2002) indicated that discharge measurements determined with LSPIV are as accurate as discharge measured using conventional methods. Bradley et al. (2002) compared discharge measurements from LSPIV and current meter methods for a stream in Iowa with a drainage area of $150 \mathrm{~km}^{2}$. The study found that differences between current meter and LSPIV discharge measurements were within the estimated standard error of the current meter. In a more recent study, Creutin et al. (2003) measured discharge in a $70 \mathrm{~m}$ cross-section of the Iowa River (22,000 $\mathrm{km}^{2}$ watershed). Their results indicated that LSPIV with a stationary remotely operated camera is capable of estimating instantaneous discharge with which to accurately and quickly construct a stage-discharge relationship.

Use of LSPIV for instantaneous flow measurements in low-order streams has several advantages. LSPIV is not as labor-intensive and does not present the safety concerns of conventional methods during high-flow events. The technology used in LSPIV is relatively inexpensive and will become even cheaper as the cost of information technology continues to decrease (Costa et al., 2002). Furthermore, LSPIV shows promise for remote monitoring applications (Bradley et al., 2002; Cruetin et al., 2003), which could also reduce labor and data management costs (Melcher et al., 2002). These cost savings could allow for the expansion of regional and state stream flow monitoring networks (Cheng et al., 2002). The increase in the geographic extent of stream monitoring would greatly enhance our understanding of the quantity and quality of our water resources.

The goal of this study was to evaluate the accuracy and feasibility of using LSPIV to measure instantaneous discharge in low-order streams. The specific objectives were: (1) to determine optimum operating parameters for applying LSPIV under various conditions, (2) to design, develop, and test a prototype under controlled laboratory conditions, and (3) to develop and test the field equipment for a variety of stream flow conditions.

\section{Materials AND Methods}

In recent years, methods have been developed for using an LSPIV system to measure discharge in open channels (Bradley et al., 2002; Cruetin et al., 2003). The USGS procedure for evaluating emerging open-channel discharge measurement technologies was used in this study (Melcher et al., 2002). In general, the methods developed in this study follow the steps shown in figure 1 and are explained in detail by Harpold (2005). Initially, an appropriate site is selected for optimum installation of the equipment using established guidelines (ISO, 1997; Rantz et al., 1982). The stream is first seeded with tracer particles that mimic the fluid movement. Subsequently, successive images of the stream surface are recorded and saved. The image quality is enhanced to improve tracer visibility, and spatial distortion is removed prior to velocity estimation. The surface velocity field is estimated using statistical correspondence methods. A representative stream velocity field is estimated by correcting the surface velocity to account for a non-uniform vertical velocity profile (ISO, 1997). After the velocity field is estimated, the channel dimensions and stage measurements are used to estimate discharge with area-velocity methods (e.g., midpoint method). In the next sections, the procedures used in this study are explained in detail.

\section{LABORATORY EXPERIMENT}

The objective of the laboratory experiment was to design, develop, and test a laboratory-scale LSPIV prototype for measuring water surface velocities and discharge in a calibrated hydraulic flume. Additionally, the prototype was tested under various conditions to identify optimum parameters prior to field evaluation. The laboratory experiments were conducted in the Biological Systems Engineering Soil and Water Resources Laboratory at Virginia Tech; see Harpold (2005) for experimental setup and equipment information. To assess accuracy, the prototype measurements were compared to discharge measurements with a $0.3 \mathrm{~m}$ wide re-circulating flume (ELD, 1987).

The laboratory data were collected in a split-plot statistical design to test the effects of three factors (seeding density, camera angle, and Froude number) on discharge accuracy. To determine the factors most affecting LSPIV discharge accuracy, an analysis of covariance (ANACOVA) was performed. If the treatment (e.g., seeding density) was shown

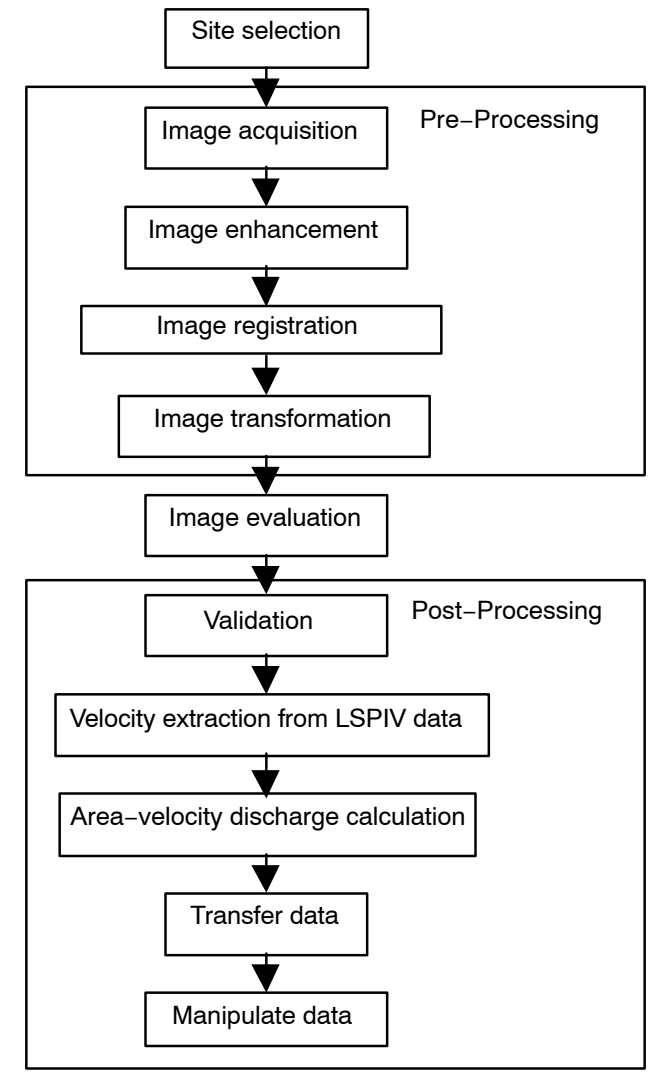

Figure 1. Flowchart showing the generalized steps involved in LSPIV, developed specifically for application of LSPIV to low-order stream discharge measurement. 
to significantly affect LSPIV discharge accuracy, paired ttests were used to assess what levels (e.g., one versus two particles per interrogation window) had a significant effect on LSPIV accuracy compared to the flume. The processes used to evaluate each factor are as follows:

- The number of particles on the water surface (seeding density) was varied to examine the effect of low seeding densities. The prototype accuracy was tested at five seeding densities, corresponding to $1,2,3,4$, and 5 particles per interrogation window.

- The effect of an oblique camera angle on LSPIV accuracy was investigated using $0^{\circ}, 15^{\circ}, 30^{\circ}$, and $45^{\circ}$ oblique angles.

- The effect of Froude number (Fr) variation was evaluated at four levels: $0.5,0.15,0.25$, and 0.35 . Froude number was selected because it identifies the flow regime $(\mathrm{Fr}<1=$ subcritical; $\mathrm{Fr}>1=$ supercritical $)$ and is a measure of the flow magnitude. Additionally, the Froude number provides an estimate of wave effects.

\section{FIELD EXPERIMENT}

The prototype was tested on two low-order streams near Blacksburg, Virginia. The streams were selected based on established guidelines for optimum discharge accuracy (ISO, 1997; Rantz et al., 1982) and the presence of a calibrated structure (weir). A total of 18 discharge measurements were collected at the two field sites from September to November 2004. At each site, discharge was also measured with a weir and area-velocity methods using a Flo-Mate 2000 current meter (Marsh-McBirney, 1990); see Harpold (2005) for all data collected. The sites have bed disturbances and can exhibit complex flows in some situations. The measurements were collected under various illumination, wind, and stage conditions. Measurements were taken throughout the day, but conditions of high surface glare were avoided. Sensitivity to reflections (image saturation) is a problem that was also encountered in previous LSPIV applications (Creutin et al., 2003). However, adverse conditions are typical in low-order streams and provided an opportunity for a more robust test of LSPIV and the assumed velocity distributions.

Discharge measurements were first collected for Stroubles Creek on the Virginia Tech campus (fig. 2). Stroubles Creek at the Duck Pond is a second-order stream that drains a $7.15 \mathrm{~km}^{2}$ watershed. The watershed is dominated by urban and suburban land uses. As a result, Stroubles Creek watershed is "flashy" with a fairly small time of concentration and increased peak flow (measured up to $1.1 \mathrm{~m}^{3} / \mathrm{s}$ ). These flow characteristics necessitated a short data collection period ( 30 to $40 \mathrm{~s}$ ) to reduce the effects of changing stage and discharge on discharge measurement accuracy. There was relatively little tree cover and associated shading problems. The camera pointed roughly east, causing some surface glare early in the day. The camera angle was approximately $30^{\circ}$ from vertical.

The second field site was Crab Creek, located on U.S. Route 11 between Christiansburg and Radford, Virginia. The measurement site was at the outlet of a $3.18 \mathrm{~km}^{2}$ agricultural watershed. Crab Creek is a third-order stream at the measurement location. The USDA installed discharge monitoring equipment at this site in 1957. However, it had not been operational (or maintained) since 1995. The LSPIV prototype used a measurement reach located roughly $30 \mathrm{~m}$ upstream of the gauging station (fig. 3). This section provided a well-defined parabolic-shaped channel with a bedrock bottom. However, this measurement reach also produced some difficulties. The reach was located downstream of a bend. The flow was accelerating outside of the bend, and there were eddy effects on the inside. In addition, riffles upstream of the measuring area produced some surface disturbances. However, this was the most suitable reach upstream of the weir. Lastly, the prototype encountered glare

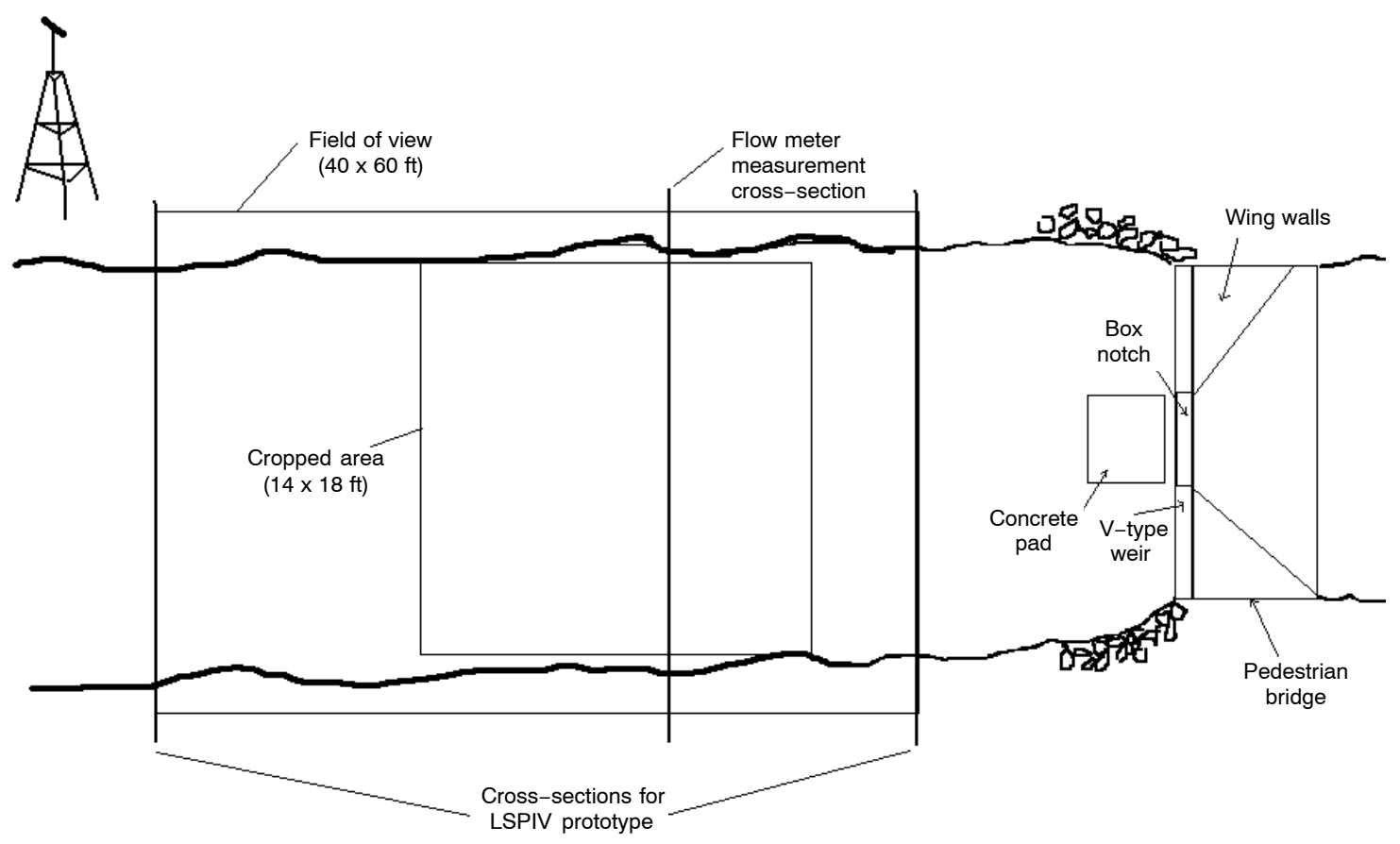

Figure 2. Schematic depicting the experimental setup on Stroubles Creek at the Duck Pond (not to scale). 


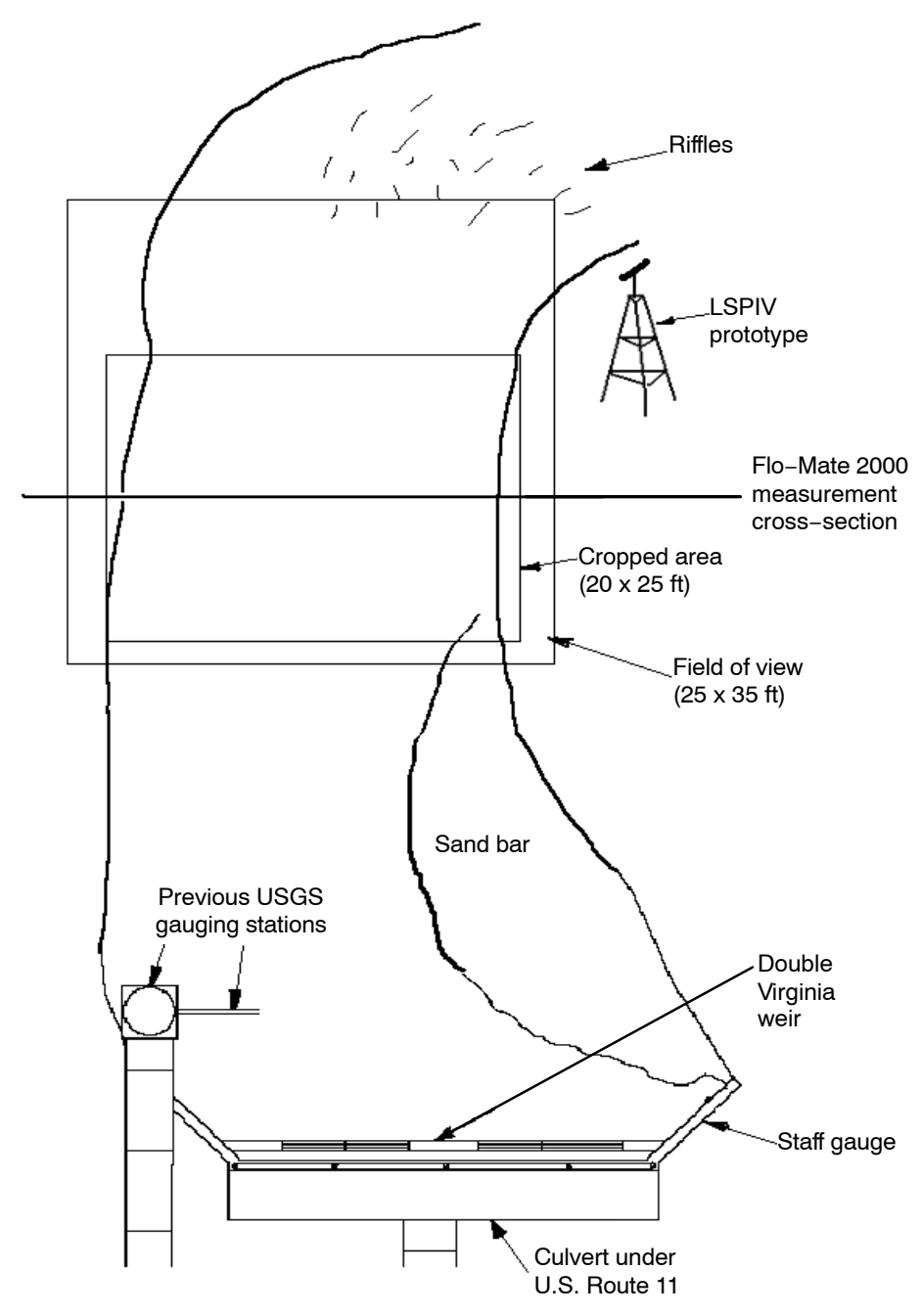

Figure 3. Schematic depicting the experimental setup at Crab Creek (not to scale). The setup was designed to maximize the accuracy of the LSPIV prototype and Flo-Mate 2000 for comparison to the site weir.

problems during midday. This is surprising because the area was well-shaded by large trees. The camera was operated at an angle of $25^{\circ}$ from vertical.

At each field site, LSPIV discharge estimates were compared to weir discharge estimates with graphical and statistical techniques. Specifically, graphical techniques were used to analyze differences in discharge estimates for the range of discharges measured, and paired t-tests were used to determine potential differences in mean discharge measured by the weir and LSPIV (Hirsch et al., 1992). The accuracy of LSPIV was also evaluated by comparing error estimates between LSPIV and the current meter. Maximum relative error and root mean square error were calculated for LSPIV and current meter estimates using the weir measurements as the true discharge.

\section{IMAGe ACQUisition}

Good image acquisition is crucial for obtaining accurate measurements with LSPIV. There are three key components to image acquisition using LSPIV. First, there must be adequate features on the stream surface to capture velocity measurements across the image plane. A homogeneous distribution of particles at a medium seeding density is optimum for image evaluation (Raffel et al., 1998), and the tracers must occupy at least one pixel. Second, the stream must be sufficiently illuminated to create contrast between the tracers and the water surface. Finally, the camera must be able to capture the image field at the desired frame rate, field of view, and resolution. Appropriate incorporation of all of these components is a prerequisite for the development of a functioning LSPIV system.

The image acquisition equipment and procedures used in the laboratory experiments were developed after an extensive review of the literature. The LSPIV prototype used white wood beads as the tracer particles, based on the laboratory work of Weitbrecht et al. (2002). The camera used in this study was a Pelco monochrome CCD camera. This camera was selected because of its high resolution $(480 \times 640$ pixels), low-light capabilities, 8-bit per pixel output (optimum for image evaluation software), and robustness for outdoor use. Additionally, an extra-wide lens (f1.4) was selected for a large field of view. The camera produced an analog output that was digitized and accessed as 8-bit black and white images using Matlab (Release 14; Mathworks, 2005). A custom-written Matlab program (Harpold, 2005) was used to collect 25 images at $25 \mathrm{~Hz}$. The high image capture rate was 


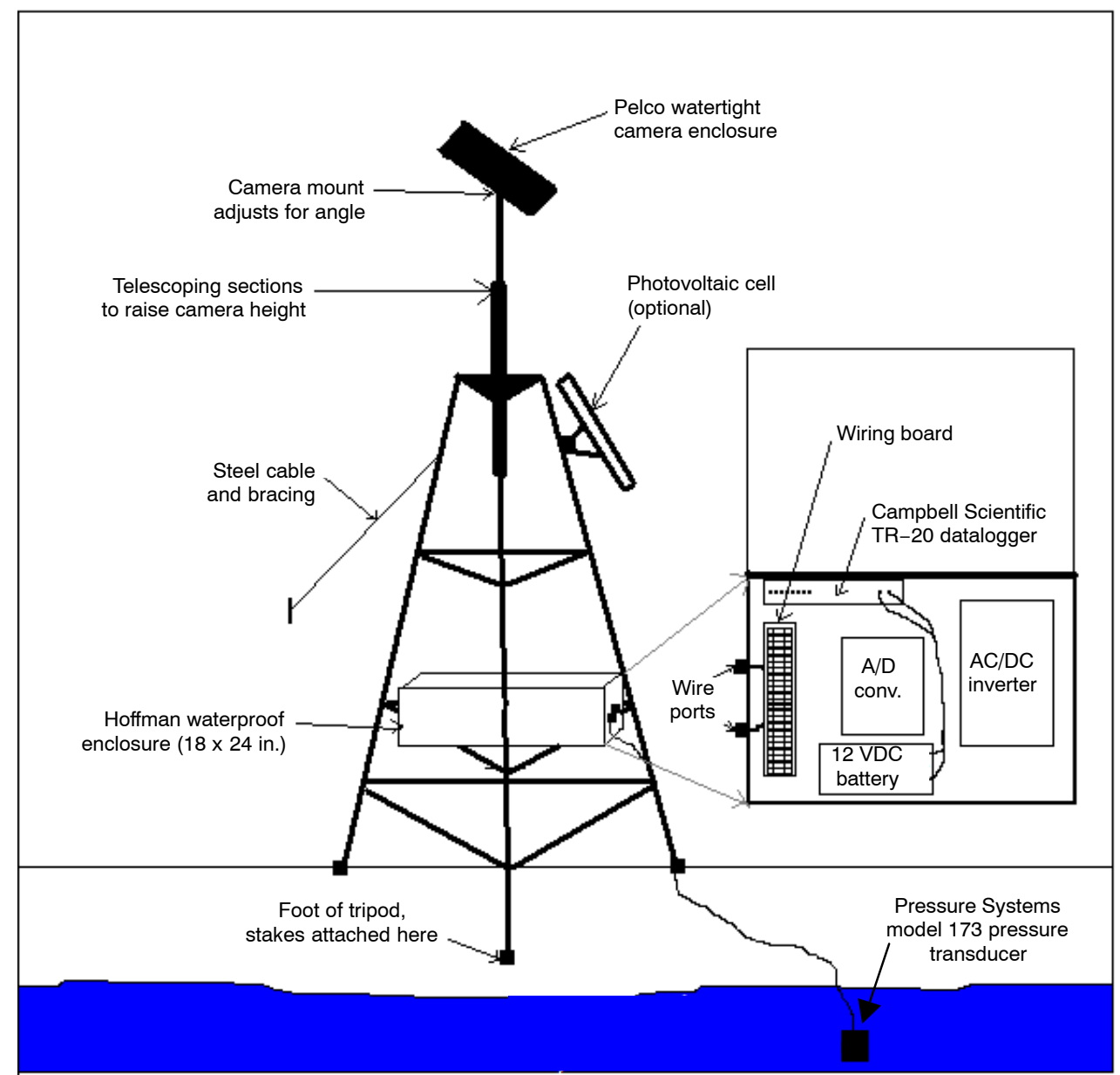

Figure 4. Schematic of the LSPIV field prototype showing the stand, waterproof box and contents, and pressure transducer (wires omitted for clarity). The prototype was capable of acquiring images and measuring stage with the assistance of a field technician.

necessary to capture reasonable pixel displacements for high velocities. A Dell Inspiron 5100 computer with 256M RAM, Pentium $4 \mathrm{CPU}$, and $2.40 \mathrm{GHz}$ operating speed was used to collect and analyze the data.

The equipment and procedures used to acquire images in the field were developed using the results from the laboratory experiments. The field prototype developed for this study is capable of measuring discharge in a variety of flow conditions and stream sizes. The prototype's hardware is mounted on a custom-made adjustable steel stand, shown in figure 4 . The image acquisition equipment was the same as that used in the laboratory experiments. A waterproof camera enclosure was necessary to protect the camera. The other hardware was stored in a waterproof enclosure mounted on the stand. The enclosure contained the wiring board that was used to run all the equipment with one 12 VDC battery and/or photovoltaic cell. The enclosure also contained a datalogger and a second 12 VDC battery to record measurements from a pressure transducer. The pressure transducer allowed accurate measurement of stage simultaneous to image acquisition.

Starch packing peanuts were used as the tracer particles in the field experiments. The starch peanuts were selected as tracers because they are environmentally friendly, contrast with the background, do not agglomerate, are very inexpensive, and are available for a variety of sizes. Starch peanuts are made by exploding starch fibers (from corn, potatoes, etc.) using heat. The partial dissolution of the particles made them less vulnerable to wind effects. The particles were applied to the water surface by hand.

In the field experiments, 40 images provided a good temporal average and reasonable computation times. Frame rates were selected to provide displacements that were optimum for the image evaluation algorithms used. The frame rate was increased at high flows (velocities) to maintain pixel displacements between 5 to 15 pixels. This was achieved, in most cases, by using frame rates ranging from 2 to $5 \mathrm{~Hz}$. However, displacements were not always optimum because of a large range of spatial scales. Selecting a frame rate is site-specific and depends on the maximum velocity and physical pixel size (Harpold, 2005).

\section{IMAGE ENHANCEMENT}

Several aspects of image acquisition can introduce error, such as poor illumination, glare, and shadows. Image enhancement methods can remove some of these errors prior to image evaluation. Image enhancement is performed by altering the pixel values of the recorded image using image-processing software. Typical image enhancement methods used in LSPIV include increasing the signal-tonoise ratio, attenuating background noise, and improving the contrast and brightness of the image (Etterma et al., 1997). Many commercial image-processing software packages can perform these common image enhancement techniques. 
However, image enhancement techniques are image specific and depend on the camera, lighting conditions, and image size.

Matlab image enhancement tools were used in both the laboratory and field images. Matlab (Release 14) provides several filters for improving contrast and increasing sharpness (Mathworks, 2004). The Matlab filter "imadjust" was used to adjust the intensity values closer to a bell-shaped curve, increasing the contrast. The command stretches the low and high values such that $1 \%$ of the data are at the extreme ends of the pixel intensity spectrum. The controlled lighting conditions in the laboratory reduced the need for advanced image enhancement techniques. In the field, this enhancement scheme proved effective in enhancing contrast (fig. 5); however, problems from glare and shadows were encountered that could not be resolved using image enhancement. The images were registered and transformed after the image enhancement was completed.

\section{REGISTRATION AND TRANSFORMATION}

In LSPIV field applications, the camera is usually at an oblique angle to the stream, which introduces spatial distortion (Bradley et al., 2002). The distortion is corrected through image transformation, which relates the pixels to their physical locations. The transformation can be corrected through implicit parameters of the camera. However, in
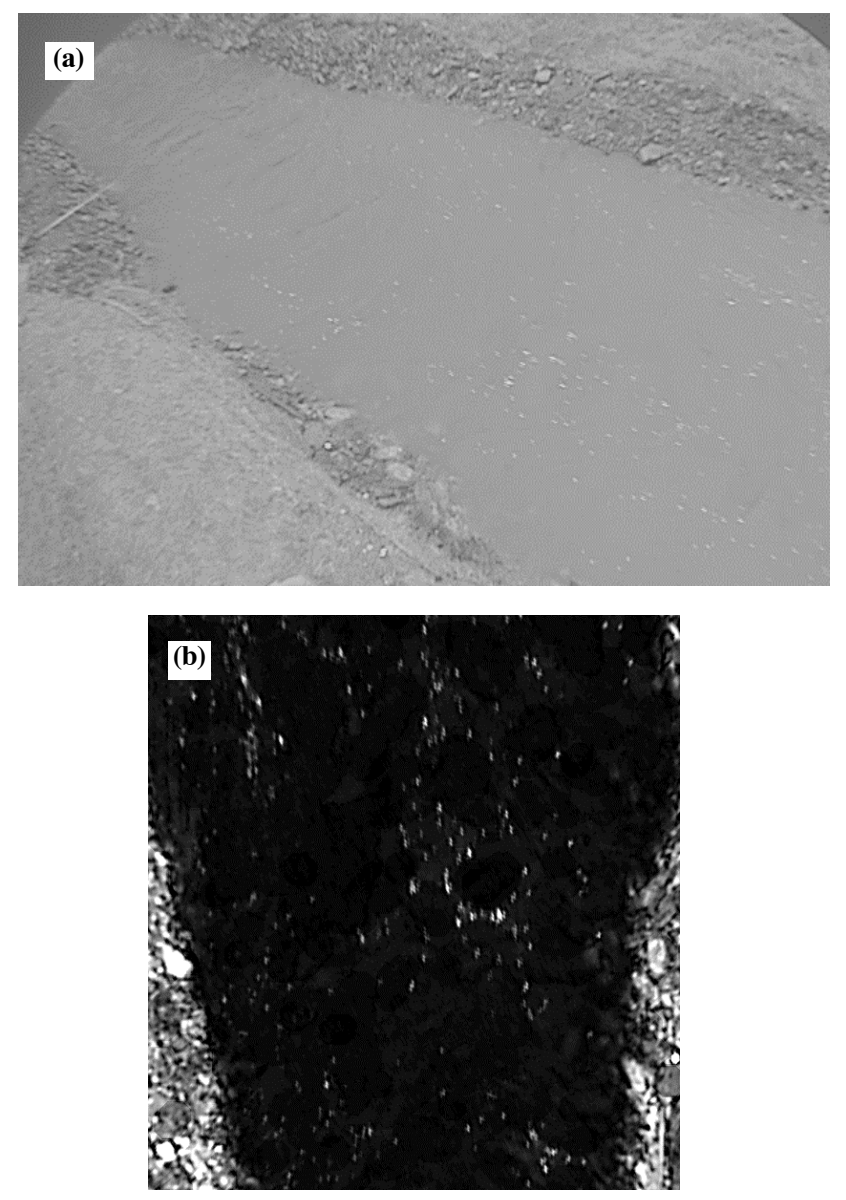

Figure 5. Results from image preprocessing that included enhancement, registration, transformation, and cropping: (a) the original image from the Duck Pond site (picture enhanced for clarity), and (b) the preprocessed image corresponding to the original image.
LSPIV applications, the transformation is explicit, as ground reference points (GRP) are used to numerically optimize the parameters (Cruetin et al., 2003). For a more detailed explanation of transformation equations, see Harpold (2005) and Fujita et al. (1998).

In the laboratory experiments, registration points were identified using a template placed in the flume prior to data collection. The template had a $1 \times 1$ in. grid pattern. Prior to the experiment, the pixel and physical locations of twelve ground reference points (GRPs) were found for all the camera angles $\left(0^{\circ}, 15^{\circ}, 30^{\circ}\right.$, and $\left.45^{\circ}\right)$. These reference points were used to create transformation equations. Matlab's localweighted mean (lwm) function was the most accurate among the methods investigated. The lwm function infers a second-order polynomial transformation function based on the six closest control points (Mathworks, 2004).

In the field experiments, GRPs were surveyed prior to the collection of images. Temporary GRPs were identified by acquiring a single image of the measurement area and identifying features at the water surface (fig. 6). The features identified were rocks, exposed bedrock, trees, and roots. The features were marked on the image, within \pm 1 pixel, using an image editing program. Subsequently, the point was surveyed with laser survey equipment. A total of 10 to 12 GRPs were taken at each site, depending on the identifiable features.

A preliminary investigation used several different Matlab functions to develop the transformation equations utilizing the GRPs collected. It was found that Matlab's "affine" function was the most accurate of the methods investigated. The affine transformation can include translation, rotation, scaling, stretching, and shearing (Mathworks, 2004). The transformation can shear the $x$ and $y$ dimensions independently, which is most appropriate for oblique camera angles. The average dimensions of the pre-processed images were approximately $550 \times 650$ pixels. The large size of the images increased the computation time to approximately $30 \mathrm{~s}$ per image. The images were analyzed to determine tracer displacements using cross-correlation algorithms.

\section{IMAGe Evaluation Using DPIV}

Image evaluation techniques use image intensity fields to measure tracer displacements and estimate a surface velocity

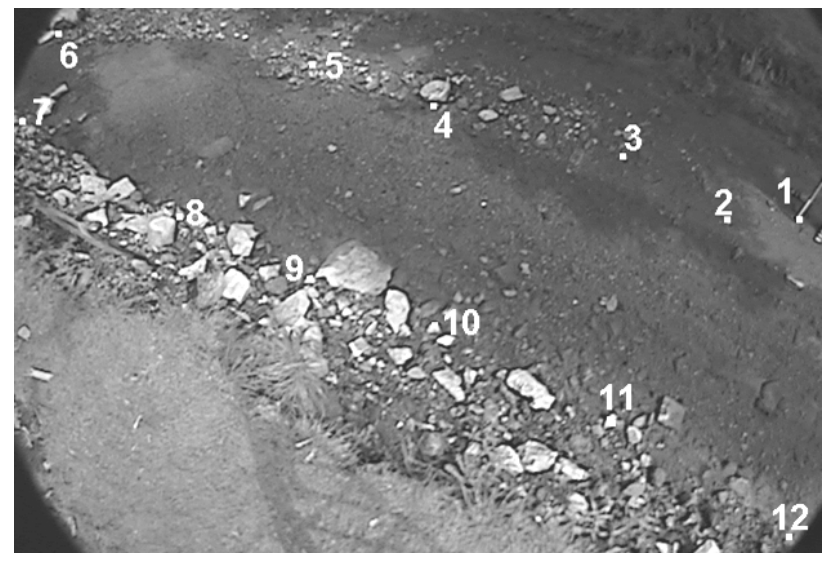

Figure 6. Twelve temporary ground reference points (GRPs) shown for the Stroubles Creek field site (picture enhanced for clarity). The points were necessary to register and transform the image to remove spatial distortion. 
field (fig. 7). Image evaluation is a critical step in LSPIV, requiring the most specialized techniques. Most LSPIV research has used correspondence techniques to determine particle displacement. Correspondence techniques, such as cross-correlation, search for the correlation of pixels (patterns and individual tracers) between frames (Bradley et al., 2002). Cross-correlation algorithms work well for the velocities and the low seeding densities found in open-channel applications (Fujita et al., 1998). Careful implementation of the algorithm and corresponding parameters is essential for accurate velocity measurements.

The PIV analysis software used in this study (FlowIQ) was developed by P. Vlachos (Abiven and Vlachos 2002a, 2002b) of Virginia Tech in collaboration with Aeroprobe Corporation. The PIV algorithms are some of the most robust available and well-tested in laboratory settings (Abiven and Vlachos, 2002a, 2002b; Brady et al., 2002). The DPIV algorithm is based on a hybrid scheme that integrates a dynamically adaptive cross-correlation method with a particle tracking velocimetry algorithm. However, in this study, seeding densities were sufficient (between two and five tracers per interrogation window) to use only the cross-correlation methods. Cross-correlation compares an interrogation area (small area of the stream surface) in one image to many interrogation areas in the corresponding image (fig. 8). A cross-correlation coefficient is calculated for every interrogation window in the search area or region of interest (ROI) (Cruetin et al., 2003). The highest correlation coefficient in the ROI is taken as the probable particle location (Bradley et al., 2002).

Effective calculation of the cross-correlation coefficients is imperative for accurate displacement measurements. Several successful LSPIV research projects (Bradley et al., 2002; Cruetin et al., 2003) have used the equation given by Fujita et al. (1998) to calculate the correlation coefficient:

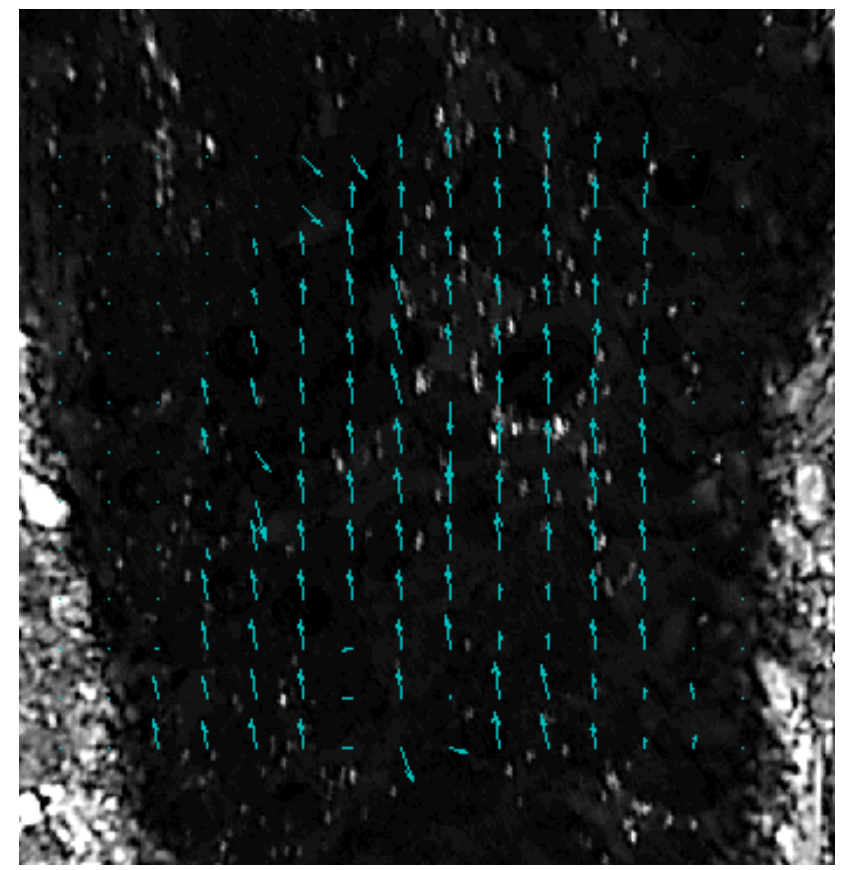

Figure 7. Typical velocity field calculated using the digital PIV program developed by P. Vlachos (DPIV version 1.0) for Stroubles Creek at the Duck Pond. After the velocity field was generated, the vectors were spatially and temporally averaged to estimate discharge. Only velocities perpendicular to the cross-section are used to estimate discharge.

$$
R_{a b}=\frac{\sum_{i=1}^{M X} \sum_{j=1}^{M Y}\left\{\left(a_{i j}-\bar{a}_{i j}\right)\left(b_{i j}-\bar{b}_{i j}\right)\right\}}{\left\{\sum_{i=1}^{M X} \sum_{j=1}^{M Y}\left(a_{i j}-\bar{a}_{i j}\right)^{2} \sum_{i=1}^{M X} \sum_{j=1}^{M Y}\left(b_{i j}-\bar{b}_{i j}\right)\right\}^{1 / 2}}
$$

where $R$ is the cross-correlation coefficient, and $M X$ and $M Y$ are the sizes of the interrogation area in each image. The variables $a_{i j}$ and $b_{i j}$ are the distributions of the gray-level values in the two interrogation areas separated by time interval $d t$. The overbar indicates the mean value of the intensity for the interrogation area. Fast Fourier transforms (FFT) were used to improve computational efficiency (Raffel et al., 1998; Adrian, 1991).

\section{Image Processing Parameters}

Several parameters must be specified prior to image evaluation, including the interrogation window size, region of interest (ROI), window-offset scheme, and grid spacing. Optimization of the interrogation window size and location is a principal means of acquiring accurate displacement measurements. The window size must be small enough to preserve the spatial scale of interest (any scale smaller than

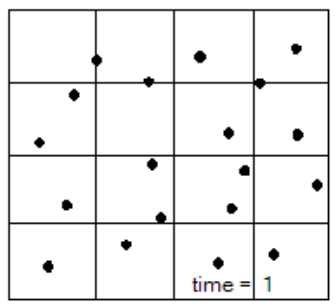

The interrogation window size controls the grid spacing that the cross-correlation coefficient will be calculated for.
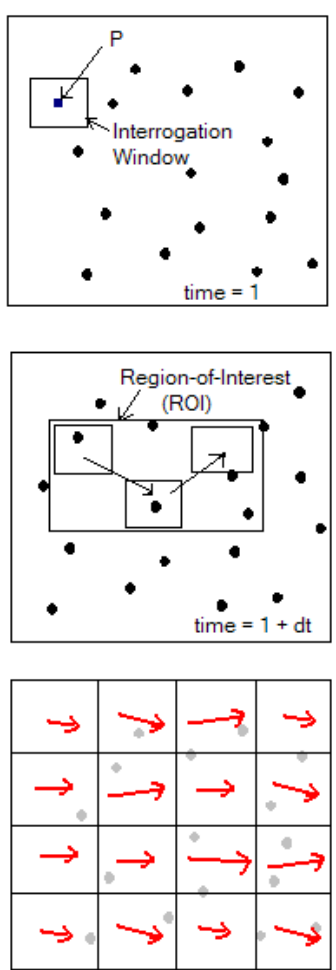

Calculating displacement for every interrogation window yields a displacement field or a velocity field that can be determined with physical pixel size and camera rate.

Figure 8. Flowchart for a typical cross-correlation algorithm. Although software programs use different algorithms, typically they follow this general flowchart. 
the window size is lost) and avoid second-order effects (e.g., displacement gradients) (Raffel et al., 1998). However, interrogation windows that are too small may suggest that many pixels show high correlation and will increase the computation time (Raffel et al., 1998). The dynamically adaptive local cross-correlation method used in this study (FlowIQ) reduces the need to precisely identify the optimum interrogation window size. The DPIV program estimates a displacement field for every point in the grid during a first pass. In subsequent passes, the size of the interrogation window is reduced and the location of the window is refined using a single-order discrete window offset; for more information on interrogation window offsets, refer to Westerweel et al. (1997) and Harpold (2005). The last operation is repeated until the user-specified minimum interrogation window size is reached. The iterative nature of this process significantly reduces the spatial averaging effects and can capture multiple length scales (Abiven and Vlachos, 2002a) often present in open-channel flow.

The ROI sizes were selected to be four times the maximum displacement in order to deliver minimum displacement error (Raffel et al., 1998). The ROI sizes varied depending on the size of the image and the average tracer displacement. The laboratory procedure used $(256,64)$ ROI window size as a first pass, and then a $(128,64)$ offset window as a second pass. The cross-correlation coefficients and corresponding displacement vectors were calculated at the user-specified grid spacing of 32 pixels. This produced a $12 \times 20$ vector surface velocity field. The image evaluation procedures were slow in the laboratory, requiring approximately $80 \mathrm{~s}$ per image pair.

The processing parameters were altered for the field experiments because of different tracer sizes and a large field of view. A 32-pixel grid spacing was used at both field sites. The Stroubles Creek site had a larger field of view, which necessitated an ROI of $(256,128)$ as a first pass, a $(256,64)$ window as a second pass, and a $(32,32)$ window as a final pass. For the smaller field of view at the Crab Creek site, the ROI window sizes were decreased. A first pass with a $(128,64)$ window was performed, followed by a second pass using a $(128,32)$ window, and a final pass using a $(16,16)$ window. Multiple ROI passes increased the range of spatial scales that could be measured and reduced the need to specify numerous ROI sizes for different flow conditions. The image evaluation procedures used in the field were markedly faster than those used in the laboratory, requiring approximately $4 \mathrm{~s}$ per image pair. The reduced computation time is the result of an improved computation scheme that was implemented in the updated version of the velocity evaluation software (J. Carneal, personal communication, May and September 2004). For additional guidance on parameter selection (i.e., interrogation window, ROI size, and grid spacing), refer to Adrian (1991).

\section{Discharge ESTIMATION}

The LSPIV velocity measurements are used to calculate discharge using the same area-velocity procedures as other devices (e.g., current meter). The most common method is to divide the measuring cross-section into several smaller sections or segments and measure velocity at each vertical. The midpoint method was used in this study; this method assumes that the depth and velocity measured at a given vertical is representative of the velocity for the partial area centered on that vertical (Rantz et al., 1982).

To properly use the midpoint area-velocity method, the stream dimensions must be surveyed (repeatedly in very dynamic systems), and stage must be measured for each discharge measurement. An upstream and downstream cross-section was surveyed, and the average of the cross-sections was used to estimate channel dimensions over the stream reach; the cross-sections used a minimum of 20 survey points. Points were collected at approximately $0.3 \mathrm{~m}$ intervals across the channel, unless changes in slope were encountered. Cross-section intervals always contained less than $10 \%$ of the total stream discharge. The midpoint method also requires the instantaneous LSPIV velocity values to be averaged temporally and spatially. The mean velocity in time was determined by averaging velocities over a set number of images (with known time intervals). Additionally, it was necessary to average velocity streamlines parallel to the flow into single-point velocities (fig. 9). Velocity also varies with depth because of the frictional forces of the bed-water and air-water interfaces. For this reason, the ISO (1997) recommends correlating the surface velocity with the velocity at 0.6 of the total water depth using correction coefficients (between 0.84 and 0.92 in natural channels). The use of a correction coefficient introduces error (see the Uncertainty Estimation section later in this article) but modifies the velocity data into the necessary form for calculating discharge.

In the laboratory, a surface correction factor of 0.95 was used to estimate average velocity from surface velocity. This value was determined from preliminary testing that indicated a parabolic vertical velocity profile. The Plexiglas flume provided minimal resistance, necessitating a smaller correction coefficient. However, at shallower depths, the velocity profile may have changed, which is not reflected in the surface correction coefficient. Additionally, the velocity data were averaged parallel to the flow into 12 velocity vectors (varied slightly depending on field of view). Subsequently, the velocity was averaged temporally across all 24 image pairs.

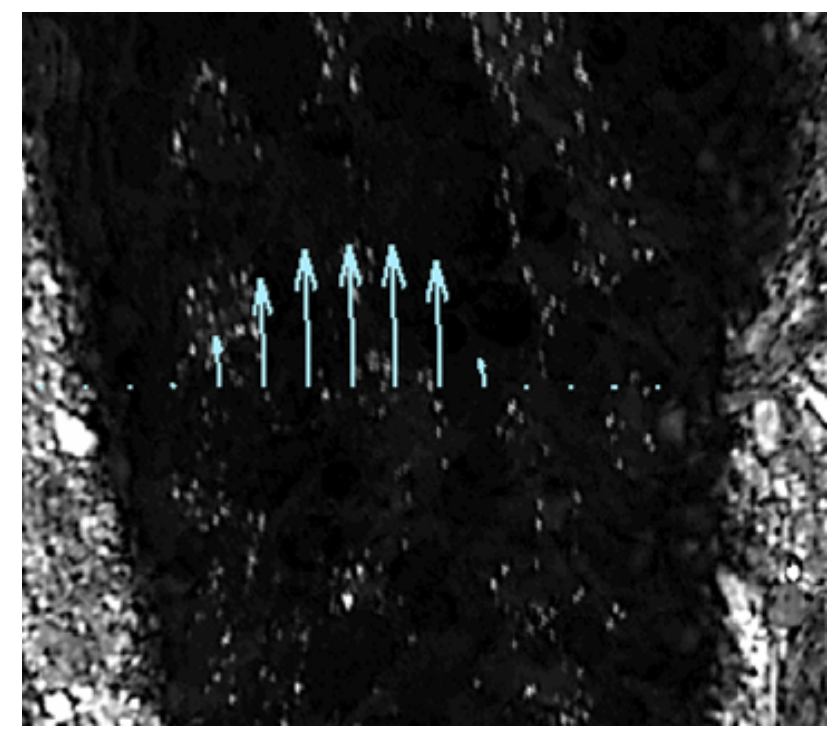

Figure 9. Cross-section LSPIV velocity vectors overlaid on enhanced image from the Stroubles Creek site. The discharge was calculated using these velocity vectors and the channel dimensions. 
The depth-averaged velocities were determined following ISO (1997) guidelines for the field measurements, with minor modifications (Harpold, 2005). Creutin et al. (2003) showed that a trend of increasing correction factors is necessary for higher stages. Therefore, a method was developed to determine the correction coefficient as a function of stage. The method assumes that the correction coefficient is 0.85 at baseflow and is 0.93 at high-flow conditions (bankfull discharge). Linear interpolation between these values was used to derive correction factors at both field sites. Additionally, the velocity data were averaged parallel to the flow into between 6 and 15 velocity vectors, depending on stage (fig. 9). Subsequently, the cross-section velocities were averaged temporally across all 39 image pairs. These velocity vectors were used in the area-velocity method to calculate discharge.

\section{Results AND Discussion}

The general goal of this study was evaluate the accuracy and feasibility of using LSPIV to measure instantaneous discharge in low-order streams, with the ultimate aim of developing a cost-effective design for widespread use. Compared to previous studies involving LSPIV in openchannel discharge measurement, this study had several unique aspects. This study included more data points than previous studies (e.g., Cruetin et al., 2003). Additionally, this was the first robust test of the LSPIV technique in low-order streams. In order to serve as an effective and economically feasible monitoring tool, a prototype was designed and constructed that can be used over a wide range of spatial scales and hydraulic conditions. In addition, the water-surface tracer particles used may be feasible for widespread use. Previous research has not identified an environmentally safe tracer particle that is applicable for different hydraulic conditions. Therefore, this research utilizes a novel method that greatly improves the applicability of LSPIV to outdoor settings. The LSPIV method was tested over a wide range of discharges in both laboratory and field settings. The results from the laboratory experiment were valuable for determining optimum operating conditions for field measurements.

\section{LABORATORY RESULTS \\ Effects of Seeding Density}

The ANACOVA results indicated that seeding density has a significant effect on the LSPIV discharge accuracy (p-value $<0.001$ ). The results showed improved accuracy relative to the flume for seeding densities of 3, 4, and 5 particles per interrogation window. Error was significantly greater for the 1 and 2 seeding densities compared to 3, 4, and 5 seeding densities using a paired t-test ( $95 \%$ confidence level) because the lack of image pairs creates zero vectors and thus underpredicts discharge. Relative error confidence intervals typically included zero for the 3, 4, and 5 particle levels at a 95\% confidence level (fig. 10), although a lack of image pairs still caused underprediction of discharge. However, the data show high variance, partly due to agglomeration at low velocities. The variance can be reduced by increasing seeding density, which should compensate for particle agglomeration. Overall, the trend of increasing accuracy with increasing seeding density is in agreement with findings of other researchers (Raffel et al., 1998; Weitbrecht et al., 2002). The results indicate that the seeding density should be maximized in field applications to avoid underprediction of discharge. Maximizing seeding density requires design of a particle dispensing device capable of releasing many particles across the entire width of the stream.

\section{Effects of Camera Angle}

Determining the effects of camera angle on LSPIV discharge measurement accuracy is useful in developing an operating range for field applications. The more oblique the camera is to the stream surface, the more error is produced in image registration and transformation. Conversely, it has been hypothesized that $0^{\circ}$ camera angles may produce bias at high Froude numbers from out-of-plane losses. Out-ofplane losses are displacements that are not captured by

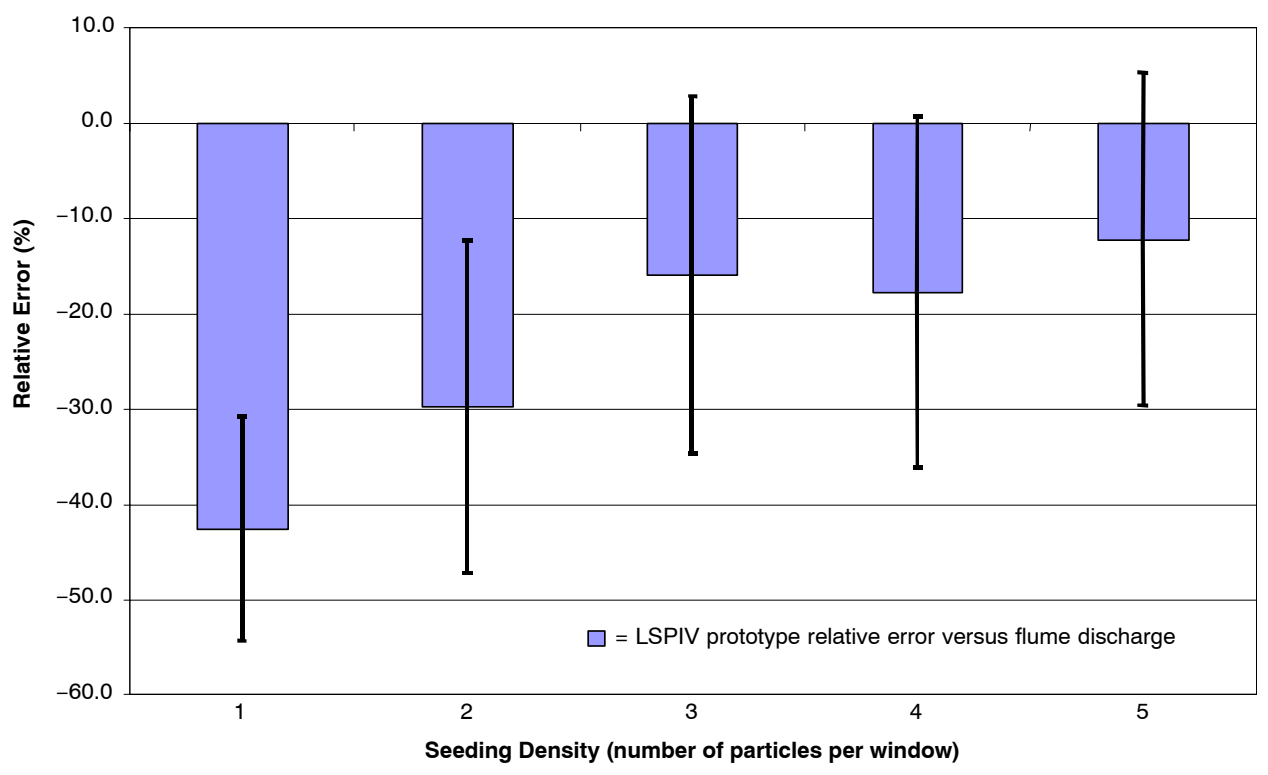

Figure 10. Relative error in discharge measurements by the LSPIV compared to the flume discharge measurements. The prototype was measured under five levels of seeding density. Error bars reflect $95 \%$ confidence intervals. 


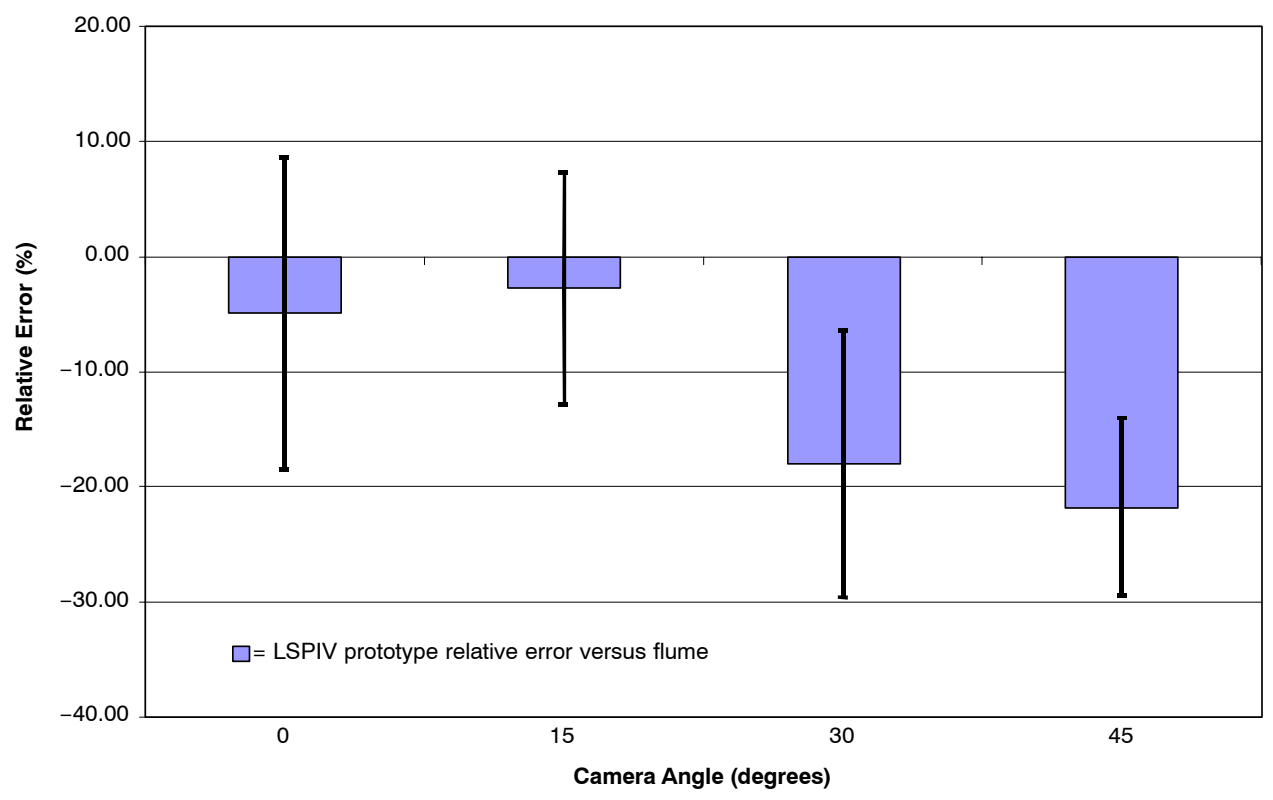

Figure 11. Relative error in discharge measurements by the LSPIV compared to the flume discharge measurements. The LSPIV prototype was measured using four camera angles. Error bars reflect $95 \%$ confidence interval.

LSPIV measurements because the motion is perpendicular to the water surface (Raffel et al., 1998). This three-dimensional movement is caused by surface disturbances, such as waves. The ANACOVA results indicated that the camera angle significantly affected the accuracy of the LSPIV measurements ( $\mathrm{p}$-value $<0.001$ ). The median LSPIV measurements underpredicted discharge at all camera angles, compared with the flume (fig. 11). The relative error for $0^{\circ}$ and $15^{\circ}$ camera angles ranged from $0.0 \%$ to $-48.1 \%$. Additionally, the $95 \%$ confidence intervals for the LSPIV discharge measurements using $0^{\circ}$ and $15^{\circ}$ camera angles contained the flume discharge (fig. 11). However, the LSPIV measurements using a $0^{\circ}$ camera angle showed higher variability at large Froude numbers. This can be attributed to outof-plane losses and resulting underestimation of the discharge. Additionally, paired t-tests showed that a camera angle of $45^{\circ}$ produced different discharges from $0^{\circ}, 15^{\circ}$, and $30^{\circ}$ angles $(\alpha=0.05)$. The results suggest that accuracy can be markedly reduced using a camera angle greater than $30^{\circ}$. Additionally, underprediction due to out-of-plane losses is possible with a $0^{\circ}$ camera angle. Based on these results, a camera angle operating range of $15^{\circ}$ to $30^{\circ}$ is recommended for field experiments.

\section{Effects of Froude Number}

The LSPIV prototype typically underestimated the flume discharges over the range of Froude numbers (fig. 12). Underpredictions were more dramatic at higher Froude numbers, while certain camera angles performed better at high Froude numbers. At the lower Froude numbers ( 0.05 and 0.15 ), the $95 \%$ confidence interval includes the flume measurement. Conversely, the greatest variance is present at these same low Froude numbers because of sporadic tracer agglomeration at low velocities. An ANACOVA showed that Froude number significantly affected both LSPIV and current meter accuracy compared to the flume discharge $(\alpha=$ $0.05)$.

The underpredictions of the LSPIV discharge measurements at high Froude numbers could have been caused by out-of-plane losses, inadequate ROI sizes, and/or inadequate seeding density. Additionally, some displacements may have occurred outside of the ROI at the highest Froude numbers (and velocities). Losses from three-dimensionality could also explain why certain camera angles showed improved results. Camera angles with moderate oblique angles (e.g., $15^{\circ}$ ) may reduce out-of-plane losses because less tracer movement is perpendicular to the field of view. Although the Froude number cannot be controlled in the field, its effect on discharge accuracy is important in site selection (Froude numbers may exceed 0.35 in steep natural channels). Areas that have surface disturbances from turbulence or upstream structures should be avoided. Additionally, bias should be considered from surface effects for a variety of stages. The underprediction problem could be solved by changing the camera angle to capture three-dimensionality, switching to a two-camera stereoscopic view, or by using a bias correction factor. The field experiments have a much larger focal length; therefore, surface disturbances may be less important in field applications.

\section{Accuracy in the Laboratory}

Overall, the LSPIV prototype measured similar discharges as the flume for the conditions investigated in the laboratory. Paired t-tests were used to compare flume and LSPIV discharge measurements under different camera angles and Froude numbers. These results indicate that the means of LSPIV and flume measurements were not statistically different at the lowest Froude number of 0.05 (p-value = 0.168), but were statistically different for all other Froude numbers. In addition, the results show that LSPIV produced mean discharge measurements with no statistical difference from the mean flume measurements using the recommended $15^{\circ}$ to $30^{\circ}$ camera angles ( $\mathrm{p}$-value $\left.=0.437\right)$. The overall accuracy of the prototype in this study was strongly influenced by testing various levels of the factors, some expected to have reduced accuracy. The discharge was measured using orifice meters fitted on the two pumps. No error information was given by the manufacturer for the 


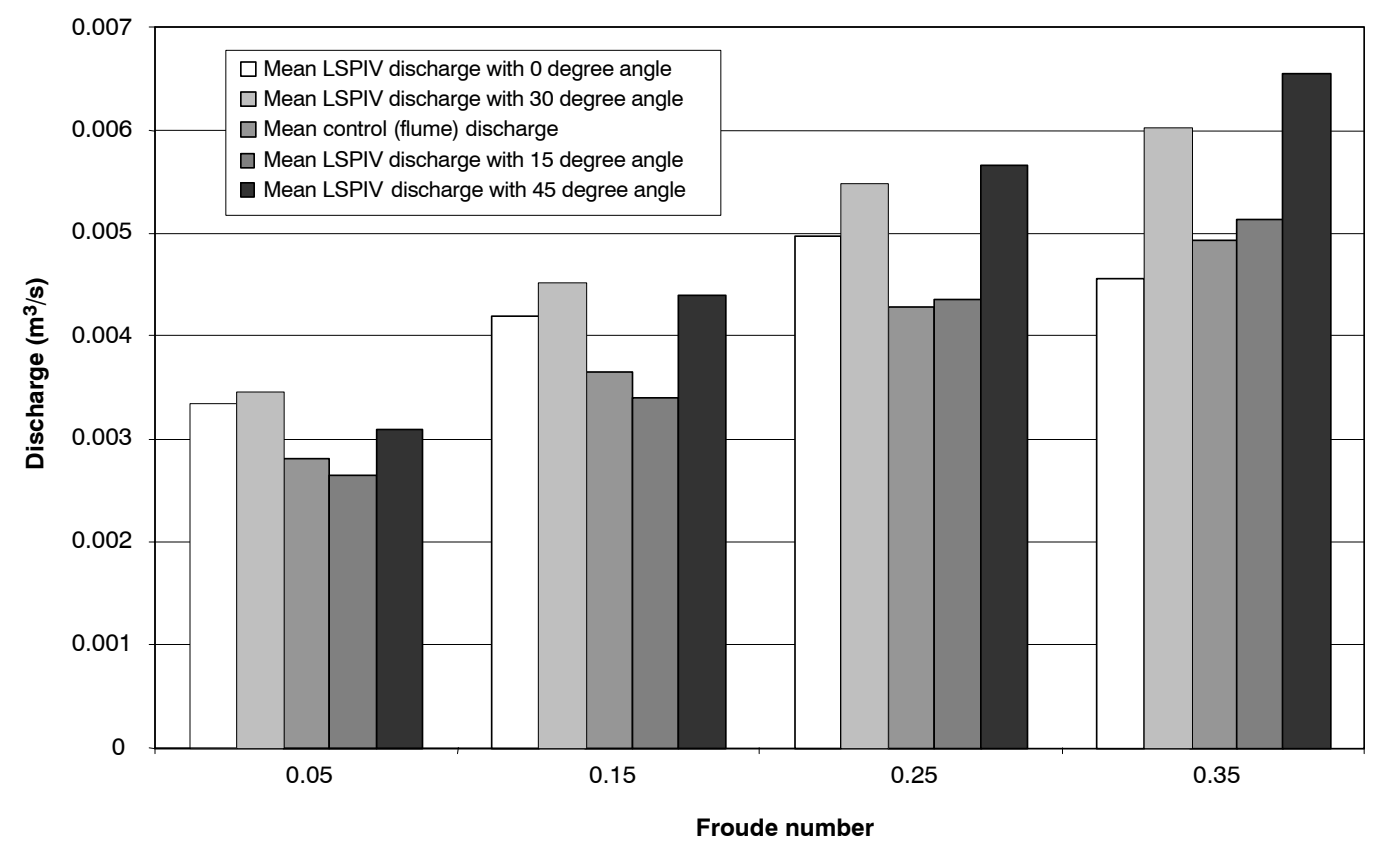

Figure 12. Mean LSPIV discharge measurement from five replications, using four levels of camera angle and Froude number. The mean flume discharges are also shown.

orifice meters. However, preliminary investigation using a Vnotch weir measured discharges within 5\% of those estimated by the flume discharge equation. Additionally, only two significant digits could be estimated for the flume discharge, which could affect the relative errors for the flow range evaluated.

\section{Field Results}

The objective of the field component of this study was to develop an LSPIV field prototype and operating procedures and analyze its accuracy under different operating condi- tions. The prototype was developed based on the equipment and methodology used in the laboratory. Additionally, a comprehensive operating procedure was developed to minimize error. A total of 18 sets of discharge measurements were collected with LSPIV, a Flo-Mate 2000 current meter (Marsh-McBirney, 1990), and a weir from 8 September to 1 November 2004 (table 1). The weir was used to directly assess the accuracy of LSPIV discharge measurements, and the current meter measurement (versus the weir) was used to evaluate LSPIV against a conventional, accepted measurement technique. During the measurement period, three tropi-

Table 1. Discharge and stage measurements made during field experiments using a weir, Flo-Mate 2000 current meter, and LSPIV prototype.

\begin{tabular}{|c|c|c|c|c|c|c|}
\hline Date and Time & $\begin{array}{l}\text { Stage } \\
(\mathrm{m})\end{array}$ & $\begin{array}{c}\text { Weir } \\
\text { Discharge } \\
\left(\mathrm{m}^{3} / \mathrm{s}\right)\end{array}$ & $\begin{array}{l}\text { LSPIV Prototype } \\
\text { Discharge } \\
\left(\mathrm{m}^{3} / \mathrm{s}\right)\end{array}$ & $\begin{array}{c}\text { Current Meter } \\
\text { Discharge } \\
\left(\mathrm{m}^{3} / \mathrm{s}\right)\end{array}$ & $\begin{array}{l}\text { Relative Error for } \\
\text { LSPIV vs. Weir } \\
\text { Discharge }(\%)\end{array}$ & $\begin{array}{l}\text { Relative Error for } \\
\text { Current Meter vs. Weir } \\
\text { Discharge }(\%)\end{array}$ \\
\hline \multicolumn{7}{|l|}{ Stroubles Creek } \\
\hline 8 Sept. 2004 10:00 & 0.56 & 1.130 & 0.810 & 0.852 & -28.3 & -24.6 \\
\hline 8 Sept. 2004 12:00 & 0.32 & 0.306 & 0.248 & 0.309 & -19.0 & 0.9 \\
\hline 8 Sept. 2004 13:00 & 0.25 & 0.125 & 0.125 & 0.122 & 0.0 & -2.6 \\
\hline 13 Oct. 2004 10:00 & 0.18 & 0.046 & 0.050 & 0.043 & 8.7 & -7.0 \\
\hline 28 Oct. 2004 9:00 & 0.15 & 0.053 & 0.051 & 0.088 & -3.8 & 65.6 \\
\hline 20 Oct. 2004 17:00 & 0.15 & 0.016 & 0.022 & 0.029 & 37.5 & 82.3 \\
\hline 22 Oct. 2004 9:00 & 0.14 & 0.012 & 0.009 & 0.026 & -25.0 & 114.8 \\
\hline 19 Oct. 2004 8:30 & 0.13 & 0.031 & 0.035 & 0.053 & 12.9 & 71.7 \\
\hline 23 Oct. 2004 12:00 & 0.12 & 0.010 & 0.009 & 0.025 & -10.0 & 149.2 \\
\hline 31 Oct. 2004 16:00 & 0.1 & 0.004 & 0.006 & 0.018 & 50.0 & 353.1 \\
\hline 1 Nov. 2004 8:00 & 0.09 & 0.003 & 0.003 & 0.016 & 0.0 & 447.5 \\
\hline Average & 0.2 & 0.158 & 0.124 & 0.144 & 2.1 & 113.7 \\
\hline \multicolumn{7}{|l|}{ Crab Creek } \\
\hline 28 Sept. 2004 11:00 & 0.56 & 1.780 & 1.521 & 0.387 & -14.6 & -78.3 \\
\hline 29 Sept. 2004 8:00 & 0.31 & 0.159 & 0.143 & 0.131 & -10.1 & -17.9 \\
\hline 29 Sept. 2004 17:30 & 0.3 & 0.068 & 0.088 & 0.070 & 29.4 & 2.5 \\
\hline 30 Sept. 2004 8:30 & 0.26 & 0.06 & 0.053 & 0.036 & -11.7 & -40.1 \\
\hline 30 Sept. 2004 18:30 & 0.26 & 0.058 & 0.047 & 0.039 & -19.0 & -33.6 \\
\hline 29 Sept. 2004 9:30 & 0.26 & 0.088 & 0.074 & 0.072 & -15.9 & -18.3 \\
\hline 5 Oct. $20048: 30$ & 0.21 & 0.020 & 0.017 & 0.019 & -15.0 & -6.5 \\
\hline Average & 0.31 & 0.319 & 0.278 & 0.107 & -8.1 & -27.5 \\
\hline
\end{tabular}


cal storms passed through the area, providing high flows and windy conditions. Stage measurements were made at both the LSPIV field of view and at the weir. Therefore, for clarity in the discussion, "stage" will refer to depth measurements made in the LSPIV field of view. Eleven discharge measurements were collected at Stroubles Creek at the Duck Pond site on the Virginia Tech campus. Stage at Stroubles Creek varied from 0.09 to $0.56 \mathrm{~m}$ during the monitoring period, with a corresponding range of discharge from 0.003 to $1.130 \mathrm{~m}^{3} / \mathrm{s}$. Seven measurements were collected at Crab Creek in Christiansburg, Virginia. Crab Creek had stage measurements from 0.21 to $0.56 \mathrm{~m}$ and discharges from 0.020 to $1.780 \mathrm{~m}^{3} / \mathrm{s}$.

\section{Uncertainty Estimation}

Estimating the uncertainty of single discharge measurements is critical for determining the relative accuracy and assessing the methods and equipment used. The uncertainties in a single determination of discharge using LSPIV come from three primary sources: velocity measurements, averaging velocity in space and time, and measuring cross-section area (Pelletier, 1988). Therefore, estimating the overall uncertainty requires accounting for all of these sources. Uncertainties were evaluated using ISO (1998) procedures. The assumptions made and corresponding references are explained in detail in Harpold (2005). The uncertainty associated with LSPIV measurements was approximately $14 \%$ of the discharge value, compared to $12 \%$ for the Flo-Mate 2000 current meter measurements. The LSPIV measurement uncertainty was due to several assumptions inherent in using LSPIV in low-order streams: the method can only measure surface velocities, it is difficult to use a large number of verticals ( $>25)$, and exposure time is limited by computer processing. In spite of these sources of error, the uncertainty associated with LSPIV was similar to that of the well-accepted method of current meter measurement. However, improvements suggested based on this research may reduce LSPIV uncertainty in subsequent applications.

\section{Accuracy in Field Conditions}

The LSPIV error was determined using a calibrated weir as the baseline (control) for both sites. The Stroubles Creek site is ideal in many ways for LSPIV application because of the simplicity of the channel, lack of major disturbances, and minimal glare problems. Therefore, it is not surprising that LSPIV showed good accuracy at this site, with a median relative error of $0.0 \%$ and a mean relative error of $2.1 \%$ (table 1). However, relative errors for LSPIV were highest at low flows, and absolute errors were highest at high flows (figs. 13 and 14). The large error at high flows may be due to the inability to maintain a constant seeding density over all image pairs. As a result, poor seeding density may have produced artificially low velocities and underpredicted discharge.

Crab Creek had more difficult measuring conditions than Stroubles Creek, and consequently more error was found in LSPIV discharge measurements at that location. The LSPIV discharge measurements from Crab Creek underpredicted discharge values, compared with weir measurements, at most stages (fig. 13). LSPIV had a median relative error of $-14.6 \%$ and a mean relative error of $-8.1 \%$ compared to the weir using seven measurements. Consistent underprediction may have been caused by channel roughness not captured with area-velocity measurements. It is possible, however unlikely, that a misreported staff gauge measurement could have lead to the outlier at $0.068 \mathrm{~m}^{3} / \mathrm{s}$. Excluding this outlier, LSPIV had a bias error of approximately $-14 \%$ at this site.

Statistical analyses were used to detect differences between the three discharge measurement techniques. Dependent group t-tests (one-way ANOVA) were used to detect differences between paired samples, using SAS Version 9.1 (SAS, 2004; Harpold, 2005). The mean weir discharge measurements (control) did not show statistical differences from the mean area-velocity measurements using the LSPIV prototype (see Harpold 2005) using a 0.95 confidence level.

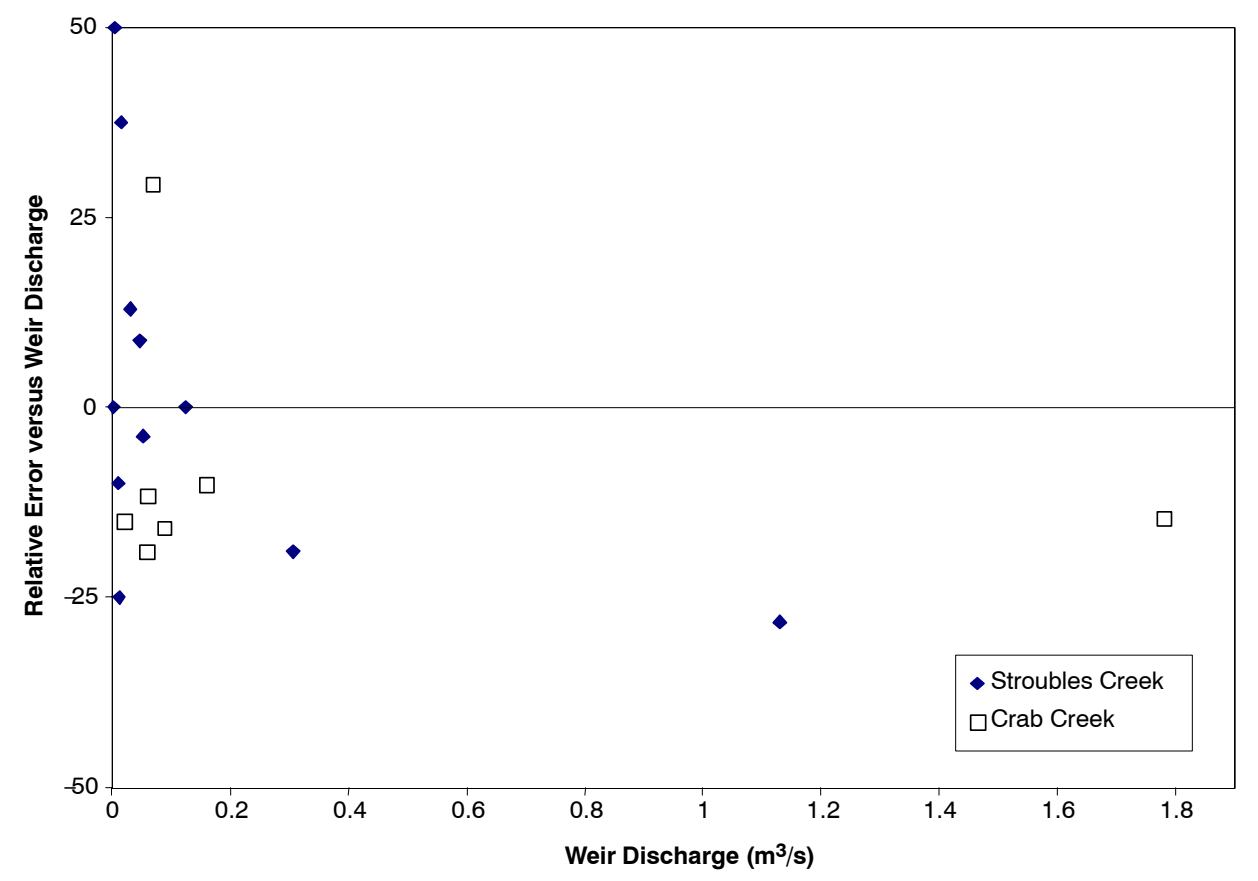

Figure 13. Relative error for LSPIV discharge measurements compared to weir measurements ( $y$-axis) versus weir discharges ( $x$-axis) for 18 discharge measurements from two sites. No clear trends are present; however, LSPIV underpredicted discharge at high stages. 


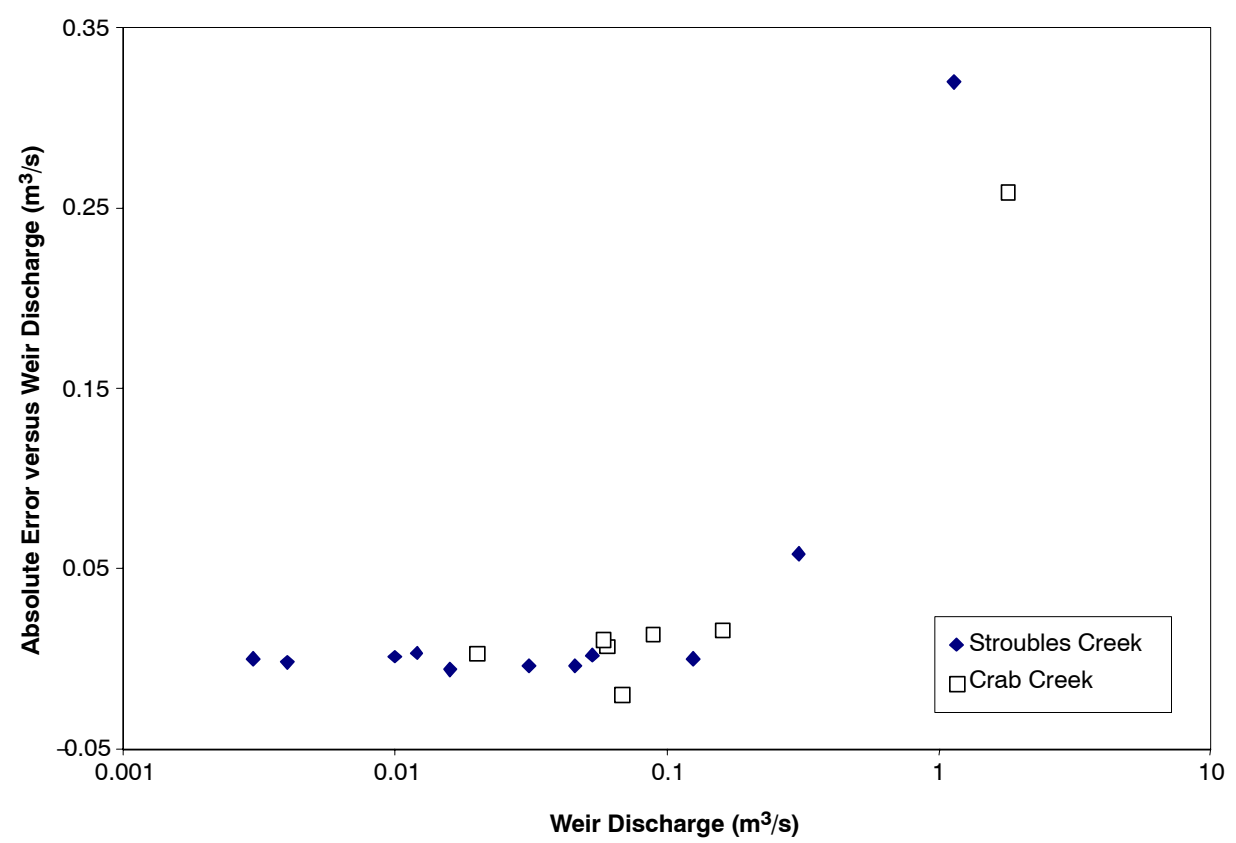

Figure 14. Absolute error for LSPIV discharge measurements compared to weir measurements (y-axis) versus weir discharges ( $x$-axis) for 18 discharge measurements from two sites. The LSPIV absolute error increased at larger discharges.

The statistical results also showed no difference between the weir discharge and the current meter discharge measurements from the weir. However, these statistical results may not indicate the absolute accuracy of LSPIV discharge measurements because of the scatter and high skew of the data points collected. Therefore, an error analysis was performed to estimate error compared to the conventional discharge estimation method of area-velocity techniques using a current meter.

To assess the accuracy of LSPIV discharge measurements, compared to the weir, the root mean square error (RMSE) was computed with the weir discharges as the true values (table 2). The RMSE show that LSPIV discharge error at Stroubles Creek was similar to the error of the current meter versus the weir. At Crab Creek, LSPIV had a much smaller error term than the area-velocity measurements using the current meter versus the weir. A considerable part of the current meter error was due to a single measurement $\left(0.387 \mathrm{~m}^{3} / \mathrm{s}\right)$ made at high flow. Although, the reasons for this outlier are not understood, it underscores the difficulty of using contact methods in high flows. Using all 18 discharge measurements, RMSE of the LSPIV versus the weir was 3.48, compared to 11.86 between the current meter and the weir. A maximum relative error was also computed to compare the

Table 2. RMSE and maximum relative error of LSPIV and current meter discharge measurements compared to a weir, for both sites and overall.

\begin{tabular}{cccccc}
\hline & \multicolumn{2}{c}{ RMSE } & & \multicolumn{2}{c}{ Maximum Relative Error } \\
\cline { 2 - 3 } \cline { 5 - 6 } & $\begin{array}{c}\text { Between } \\
\text { Current Meter } \\
\text { and Weir }\end{array}$ & $\begin{array}{c}\text { Between } \\
\text { LSPIV } \\
\text { and Weir }\end{array}$ & & $\begin{array}{c}\text { Between } \\
\text { Current Meter } \\
\text { and Weir }\end{array}$ & $\begin{array}{c}\text { Between } \\
\text { LSPIV } \\
\text { and Weir }\end{array}$ \\
\hline $\begin{array}{c}\text { Stroubles } \\
\text { Creek }\end{array}$ & 3.01 & 3.46 & & 0.42 & 0.34 \\
\hline $\begin{array}{c}\text { Crab } \\
\text { Creek }\end{array}$ & 18.65 & 3.52 & & 0.95 & 0.18 \\
\hline Both sites & 11.86 & 3.48 & & 0.95 & 0.34 \\
\hline
\end{tabular}

maximum error between the measurement techniques. Again, LSPIV showed less error than the current meter, when compared to the weir, at both sites and overall. The error analysis shows that LSPIV discharge measurements are comparable to conventional methods (area-velocity method using a current meter) when a weir is used as the baseline (control).

When compared to weir discharge measurements, the error associated with LSPIV was relatively low and comparable to a conventional discharge measurement (current meter) technique. However, the LSPIV data tended to underpredict the weir measurements over the range of discharges measured. This trend is in agreement with the work of Cruetin et al. (2003), which measured discharges from 48.1 to $283 \mathrm{~m}^{3} / \mathrm{s}$. It is hypothesized that the underpredictions are due to out-of-plane losses, low seeding densities, or displacements occurring outside of the ROI. Consistent LSPIV discharge underprediction across the range of stages (as evidenced in the Crab Creek data) would probably indicate that out-ofplane losses are not responsible for the poor accuracy. Instead, low seeding densities are the probable cause of the LSPIV discharge underpredictions. Additionally, Cruetin et al. (2003) found "random" outliers that greatly overpredicted flow discharge (up to 39\%). The LSPIV data from Crab Creek, and to a lesser extent those from Stroubles Creek, also had unexplained discharge overpredictions. Overall, the LSPIV discharge measurements had a median relative error of $-10.0 \%$ and a mean error of $-1.9 \%$, compared to the weir. These errors are similar to those found by Bradley et al. (2002) of $\pm 6.0 \%$, versus area-velocity measurements using a current meter, for a single discharge measurement of $0.190 \mathrm{~m}^{3} / \mathrm{s}$ (150 $\mathrm{km}^{2}$ drainage area). In addition, the magnitude of the error is similar to those found by Cruetin et al. (2003), which showed a small error compared to a weir. Finally, Fujita et al. (1998) reported measurement errors of $\pm 3 \%$ for a much larger discharge $\left(3540 \mathrm{~m}^{3} / \mathrm{s}\right)$. Therefore, the results of this study are consistent with past research and highlight the importance of sufficient data in assessing LSPIV discharge accuracy in varied conditions. 


\section{SumMARY AND CONCLUSION}

Current limitations of conventional discharge measurement techniques were the impetus for investigating the potential for using large-scale particle image velocimetry (LSPIV). Based on the analysis of the data collected in this study, several conclusions can be drawn concerning the application of LSPIV to measure discharge in low-order streams:

- Stream flow conditions affect the accuracy of LSPIV discharge measurements. At Froude numbers $>0.25$, LSPIV may show out-of-plane displacement losses (especially at smaller focal lengths) and/or inadequate seeding densities, which will cause underestimation of the actual discharge. At Froude numbers $<0.10$, tracer particles are more likely to agglomerate and reduce the LSPIV measurement accuracy by up to $15 \%$.

- Improper camera angles can be a source of error in LSPIV discharge measurements. Operating the camera orthogonal to the water surface may exacerbate out-ofplane losses; however, image distortion may not be adequately corrected at angles significantly above $30^{\circ}$ from vertical. Therefore, a camera angle operating range of $15^{\circ}$ to $30^{\circ}$ is recommended for field applications.

- Adequate seeding density is an extremely important factor in obtaining accurate LSPIV measurements. Seeding densities above three particles per interrogation window should produce satisfactory results. However, variance in LSPIV measurements can be drastically reduced using seeding densities near five particles per interrogation window, especially at high velocities.

- The LSPIV discharge measurements were similar to weir measurements for the flow conditions tested in this study. A mean error of less than $10 \%$ resulted, which is consistent with previous LSPIV research. Furthermore, the accuracy of LSPIV was comparable to current meter measurements.

- Based on two measurements of relatively high flow (1.1 to $\left.1.7 \mathrm{~m}^{3} / \mathrm{s}\right)$, the LSPIV measurements had poor accuracy, with errors of $-15 \%$ and $28 \%$, compared to the control structure. High-flow conditions produce complex flow patterns, which may invalidate some of the velocity distribution assumptions used in area-velocity discharge estimation methods. Additionally, maintaining good seeding density and distribution can be more difficult at high flows.

- The proof-of-concept showed that LSPIV is capable of providing accurate discharge measurements in low-order streams. Additionally, the LSPIV system shows promise for replacing conventional discharge measuring techniques with a less labor-intensive alternative. However, improvements in automation and reducing measurement uncertainty are necessary for widespread application and/or commercial viability.

- The development of an accurate and cost-effective LSPIV system could improve and expand surface water monitoring networks. Additionally, LSPIV has the potential for real-time open-channel flow monitoring. The possible benefits of a successful LSPIV system should encourage future work into resolving the limitations illustrated in this study.

\section{ACKNOWLEDGEMENTS}

The authors of this study would like to thank the Virginia Water Resources Research Center for its financial support, NSF REU students Cami Johnson and Sean Tolle, the staff and graduate students of the Department of Biological Systems Engineering at Virginia Tech, and Dr. Vlachos' research group and Aeroprobe Corporation for the use of the DPIV software. Finally, the authors would like to thank the anonymous reviewers and the diligent work of the associate editor for greatly improving the manuscript.

\section{REFERENCES}

Abiven, C., and P. Vlachos. 2002a. Comparative study of established DPIV algorithms for planar velocity measurements. In Proc. ASME IMECE 2002. New York, N.Y.: American Society of Mechanical Engineers.

Abiven, C., and P. Vlachos. 2002b. Super spatio-temporal resolution, digital PIV system for multi-phase flows with phase differentiation and simultaneous shape and size quantification. In Proc. ASME IMECE 2002. New York, N.Y.: American Society of Mechanical Engineers.

Adrian, R. 1991. Particle-image techniques for experimental fluid mechanics. Annual Review of Fluid Mechanics 23: 261-304.

Bradley, A. A., A. Kruger, and M. Muste. 2002. Flow measurement in stream using video imagery. Water Resources Res. 38(12): 512-518.

Brady, M., C. Abiven, P. Vlachos, and G. Papadopoulos. 2002. Time-resolved spray-droplet velocity and size measurement via single camera laser sheet imaging a planar DPIV. In Proc. ASME IMECE 2002. New York, N.Y.: American Society of Mechanical Engineers.

Cheng, R., J. Costa, P. Haeni, N. Melcher, and E. Thurman. 2002. In In Search of Technologies for Monitoring River Discharge, 203-219. Denver, Colo.: Colorado Water Resources Publications.

Costa, J. E., K. R. Spicer, R. T. Cheng, P. F. Haeni, N. B. Melcher, and M. E. Thurman. 2002. Measuring stream discharge by non-contact methods: A proof-of-concept experiment. Geophysical Research Letters 27(4): 553-556.

Creutin, J. D., M. Muste, A. A. Bradley, S. C. Kim, and A. Kruger. 2003. River gauging using PIV techniques: A proof-of-concept experiment on the Iowa River. J. Hydrology 277(3-4): 182-194.

ELD. 1987. B-16 Hydraulic Demonstration Channel: Installation, Operation, and Maintenance Manual. Lake City, Minn.: Engineering Laboratory Designs, Inc.

Etterma, R., I. Fujita, M. Muste, and A. Kruger. 1997. Particle-image velocimetry for whole-field measurement of ice velocities. Cold Region Sci. and Tech. 26: 97-112.

Fujita, I., M. Muste, and A. Kruger. 1998. Large-scale particle image velocimetry for flow analysis in hydraulic engineering applications. J. Hydraulic Res. 38(3): 397-414.

Grant, I. 1997. Particle image velocimetry: A review. In Proc. Inst. Mech. Engrs. 211 Part C: 55-76.

Harpold, A. 2005. Discharge measurement in streams using a large-scale particle image velocimetry prototype. MS thesis. Blacksburg, Va.: Virginia Tech, Department of Biological Systems Engineering.

Herschy, R. W. 2002. Editorial to: Open channel flow measurement. Flow Measurement and Instrumentation 13(5-6): 189-190.

Hirsch, R. M., D. R. Helsel, T. A. Cohn, and E. J. Gilroy. 1992. Statistical analysis of hydrologic data. In Handbook of Hydrology, 17.1-17.55. New York, N.Y.: McGraw-Hill.

ISO. 1997. ISO 748: Measurement of liquid flow in open channels: Velocity area methods. Geneva, Switzerland: ISO.

ISO. 1998. ISO 5168: Measurement of fluid flow: Evaluation of uncertainties. Geneva, Switzerland: ISO. 
Marsh-McBirney. 1990. Model 2000 Operations and Instructions Manual. Frederick, Md.: Marsh-McBirney, Inc.

Mathworks. 2004. Matlab Version 7.0 Help. Natick, Mass.: The Mathworks, Inc.

Melcher, N. B., J. E. Costa, F. P. Haeni, R. T. Cheng, E. M. Thurman, M. Buursink, K. R. Spicer, E. Hayes, W. J. Plant, W. C. Keller, and K. Hayes. 2002. River discharge measurements by using helicopter-mounted radar. Geophysical Res. Letters 29(22): 411-414.

Pelletier, P. 1988. Uncertainties in the single determination of river discharge: A literature review. Canadian J. Civil Eng. 15: 834-850.

Raffel, M., C. Willert, and J. Kompenhans. 1998. Particle Image Velocimetry: A Practical Guide. New York, N.Y.: Springer.
Rantz, S. E., et al. 1982. Measurement and computation of streamflow: Volume 2. Computation of discharge. USGS Water Supply Paper 2175, 1982b. Washington, D.C.: U. S. Geological Survey.

SAS. 2004. SAS Version 9.1 User's Guide. Cary, N.C.: SAS Institute, Inc.

Weitbrecht, V., G. Kuhn, and G. H. Jirka. 2002. Large-scale PIV measurements at the surface of shallow water flows. Flow Measurement and Instrumentation 13(5-6): 237-245.

Westerweel, J., D. Dabiri, and M. Gharib. 1997. The effect of a discrete window offset on the accuracy of cross-correlation analysis of digital PIV recordings. Experiments in Fluids 23(1): 20-28.

Yorke, T. H., and K. A. Oberg. 2002. Measuring river velocity and discharge with acoustic Doppler profilers. Flow Measurement and Instrumentation 13(5-6): 191-195. 
